\title{
Two-Stage Concrete as a Sustainable Production
}

\author{
H. S. Abdelgader ${ }^{1}$, A S. El-Baden ${ }^{1}$, H. A. Abdurrahman ${ }^{2}$, and A. S.M. Abdul Awal ${ }^{3}$ \\ ${ }^{1}$ University of Tripoli, Department of Civil Engineering, Tripoli, Libya \\ ${ }^{2}$ Florida Institute of Technology, Department of Civil Engineering, Melbourne, USA \\ ${ }^{3}$ University of Tun Hussein Onn Malaysia, Faculty of Civil and Environmental Engineering, Johor, Malaysia
}

\begin{abstract}
Two-stage concrete (TSC) is a sustainable concrete which is produced by forcing a flowable cement grout mixture through the voids of a skeletal mass made of compacted preplaced aggregates. From the technical and economic aspects, TSC is particularly useful for construction and repair of concrete structures especially foundations, underwater construction, nuclear reactors, concrete dams, heritage structures and in constructions with closely spaced reinforcement. TSC differs from ordinary concrete in that it contains a higher proportion of stone aggregate and the aggregate stays in point-to-point contact as placed. Thus, the mechanical characteristics of the TSC in failure conditions are distinctly different from ordinary concrete. This paper presents the results of experimental investigations conducted to evaluate the compressive, tensile strength and modulus of elasticity of TSC using grouts with different water-to-cement ratios and admixture contents. It was found that the modulus of elasticity and splitting tensile strength of TSC are equivalent or higher than that of conventional concrete at the same compressive strength. In this method of construction, the splitting tensile strength can be conservatively estimated using the American concrete institute (ACI) equation for conventional concrete.
\end{abstract}

\section{Introduction}

The preplaced aggregate concrete (PAC) or two-stage concrete (TSC) gets its name from the method used for placement. Formwork is constructed and the coarse aggregate is densely placed inside the formwork. Grout is then injected through the forms to provide the matrix as shown in Figure 1. Grouting is made at the bottom of the preplaced aggregate [1]. The grout typically consists of sand, cement, water, and an admixture. For each mixture there are optimum amounts of fillers and admixtures which produce the best pumpability or consistency. Proper proportioning of the structural grout mix components is necessary to produce the required strength and durability requirements of the finished preplacedaggregate concrete [2]. It may be used advantageously on repair jobs of heritage structures, and large concrete repair jobs:

- Where placement by conventional methods is difficult (e.g., massive reinforcing steel and embedded items are present or access to the area is difficult, such as the underpinning of the toe of a dam or apron).
- When low-volume change of the repair concrete is required to avoid cracking caused by excessive tensile stresses in the overlay concrete because of drying shrinkage and restraint provided by the existing concrete. - Where underwater placement is necessary because dewatering is difficult, expensive, or impractical.

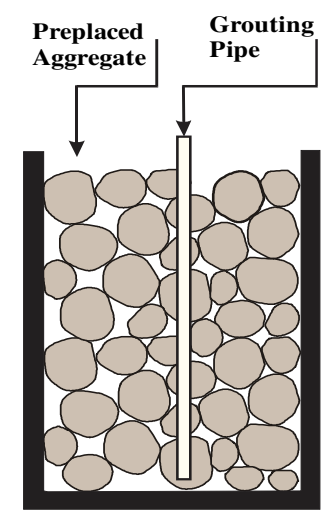

(a)

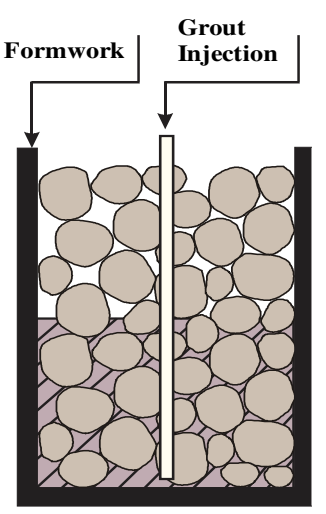

(b)
Fig. 1. Fundamental Techniques of TSC 
In the last decades, TSC has been involved in many typical applications across the globe. For example, in Poland large-scale two-stage concreting was tested in two applications, namely while laying foundations for an 18 story building in Gdansk (Poland) (about $350 \mathrm{~m} 3$ ) and the repair of damage to a water dam in Czchow near Cracow (Poland) (about 400m3) underwater concreting, on the River Dunajec. In both cases good technological and economical results were obtained [3].

The two-stage concrete has been proved to be essential as radiation shielding in nuclear power plants where heavy weight aggregates are normally used as coarse aggregate. The controversy over the use of nuclear energy fundamentally comes down to three main considerations: its safety of use, ability of nuclear energy generation to reduce greenhouse gas emissions and finally its long term sustainability. In this regard, two-stage method of concrete production appears to be the best choice that promises better environmental performance than conventional concrete in the material production stage by saving a large amount of cement $[4,5]$.

This paper presents the output results of experimental investigations conducted to evaluate the compressive, tensile strength and modulus of elasticity of TSC using grouts with different water-to-cement ratios and admixtures content. It was found that the modulus of elasticity and splitting tensile strength of TSC is equivalent or higher than that of conventional concrete at the same compressive strength.

\section{Experimental program}

\subsection{Materials and grout proportioning}

The coarse aggregate used in the experiment program was sub-angular basalt. A large sample was acquired, washed, and sieved to create the gradation with a maximum size of $50 \mathrm{~mm}$. The coarse aggregate had a bulk loose density $1430 \mathrm{~kg} / \mathrm{m} 3$, dry specific gravity of 2.687, absorption of $0.34 \%$, and void ratio of $47 \%$. Because of its low absorption and high apparent specific gravity, this basalt is considered a high quality coarse aggregate. The fine aggregate used had an absorption and specific gravity of $1.05 \%$ and 2.63 respectively. The particle size distribution of the sand was divided into three fractions: $2.0 / 1.0 \mathrm{~mm}(13 \%), 1.0 / 0.25 \mathrm{~mm}(67 \%)$, and $0.25 / 0.0 \mathrm{~mm}(20 \%)$. Its properties were checked in accordance to standards [6]. The cement used throughout the research was ordinary (Type I) Portland cement, having a compressive strength of $41 \mathrm{MPa}$ after 28-days of water curing and Blaine fineness of approximately 3500 $\mathrm{cm} 2 / \mathrm{g}$. The cement properties conformed to standards [7].Water was used directly from the tap and was slightly colder (21OC) than room temperature. The superplasticizer used in the grout was a naphthaleneformaldehyde derivative, trade name 'SikaMent-163' and was mixed at the rate of $2 \%$ by weight of cement. The selection of water-cement-sand ratios is more critical in TSC because the amounts of sand and water control the pump-ability and propagation of grout [8]. The void content of the preplaced aggregate was $47 \%$ and the bulk density $1430 \mathrm{~kg} / \mathrm{m} 3$. Five different proportions of water to cement ratio $(\mathrm{w} / \mathrm{c})(0.42,0.45,0.50$ and 0.55$)$ were investigated with cement to sand ratios $(\mathrm{c} / \mathrm{s})$ of $1 / 1.5,1 / 1$, and 1/0.8. Grout preparation was accomplished by combining ingredients with an electric mixer for about three minutes to achieve the desired grout uniformity and consistency. After trials, a w/c ratio of 0.45 was found to be the minimum ratio suitable for grouting. The displacement of aggregate was less noticeable as the w/c ratio was increased; at a w/c ratio of 0.55 there was no displacement.

\subsection{Specimen preparation and testing set-up}

Three specimens from each one of the three grout mixtures were tested in unconfined compression, split tension and modulus of elasticity at 28 days. A separate set of 27 concrete cubes of size $300 \times 300 \times 300 \mathrm{~mm}$ were tested for compressive strength only using grout having w/c ratio of $0.45,0.5$ and 0.55 and sand cement ratio of $1 / 1.5,1 / 1$ and 1/0.8. Mortar cubes were prepared and tested in unconfined compression as prescribed in standards [9]. Three cubes of each mortar were tested at 28 days. Unconfined compression tests on TSC cylinders were tested in accordance with standards [10]. Splitting tensile tests were also conducted on three specimens of each concrete at 28 days according to the procedures outlined in [11]. Splitting tensile tests were performed using the same machine as the mortar cubes.

\section{Strength investigations}

\subsection{Compressive Strength}

Three cylinders from each concrete mix were sub-jected to an unconfined compression test. During the loading procedure, the vertical deformations were measured on three sides of the specimen with respect to axial force increment. On the basis of these results, stress and appropriate strain values were calculated. Some of the test results are presented in Figure 2. Compressive strength results from the cubical shape samples are presented in Table 1.

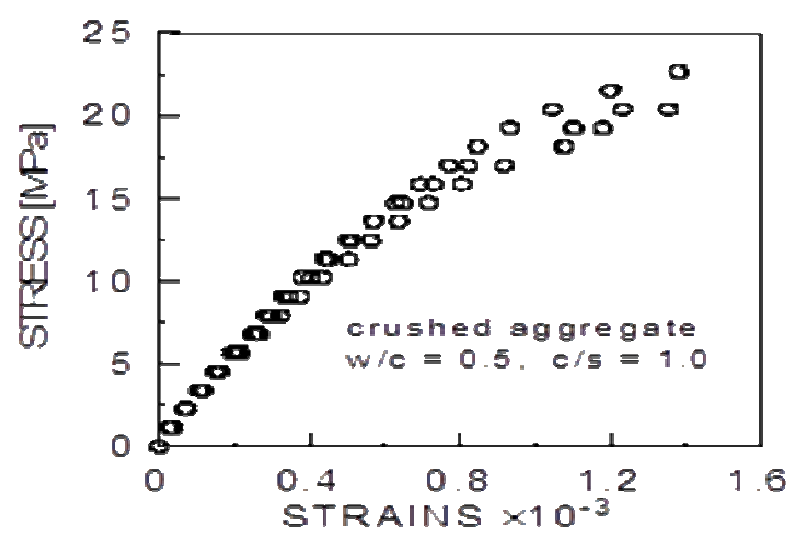

Fig. 2. Stress-strain sample of results for TSC 
Table 1. Compressive strength of TSC

\begin{tabular}{|c|c|c|}
\hline W/C & \multirow{2}{*}{$\mathrm{S} / \mathrm{C}$} & $\begin{array}{c}f_{\mathrm{c}}^{\prime} \\
(\mathrm{MPa})\end{array}$ \\
\hline 0.45 & \multirow{3}{*}{$1 / 1.5$} & 30.82 \\
\cline { 1 - 1 } 0.45 & & 27.82 \\
\hline 0.45 & & 23.72 \\
\hline 0.5 & \multirow{2}{*}{$1 / 1$} & 30.65 \\
\hline 0.5 & & 27.10 \\
\hline 0.5 & & 23.55 \\
\hline 0.55 & \multirow{3}{*}{$1 / 0.8$} & 30.78 \\
\hline 0.55 & & 27.23 \\
\hline 0.55 & & 23.68 \\
\hline
\end{tabular}

Figure 3 shows the mean and individual cylinder strengths of three specimens per w/c ratio at ages of 28 days. It can be seen that a mean compressive strength of 31.9 is attainable at 28 days with a w/c ratio of 0.45 .

Figure 3 demonstrates a strength reduction as the w/c ratio increases. Although there is some variation in strength measured per w/c ratio, the strength reduction is approximately linear. This observation is consistent with unconfined compressive strength measurements of TSC cube specimens $(300 \times 300 \times 300 \mathrm{~mm})$, in previous work for the author [12] where the compressive strength (fc') of TSC at 28 days determined by Equation (1) as shown earlier in Table 1.

$$
f_{c}^{-}=62.08-71.00(w / c)+0.52(c / s)
$$

Equation (1) is illustrated in Figure 3 for a cement/sand $(\mathrm{C} / \mathrm{S})$ ratio of 1.0 , and it can be seen that it under-predicts strength of the cylindrical specimens tested in this program. The predicted mean strength from Equation (1) is 87 to $93 \%$ of the measured mean strength. Decreasing the multiplicative factor on the w/c ratio in Equation 1 to account for cylindrical specimens yields Equation (2) as the following:

$$
f_{c}^{-}=62.08-68.00(w / c)+0.52(c / s)
$$

Only $\mathrm{c} / \mathrm{s}=1.0$ for specimens investigated herein. Further research is required to determine the suitability of Equation (2) for a range of c/s ratios. Another significant finding from the compressive strength data was the somewhat limited rate of strength development. This can be explained, in part, because of the fact that no fly ash or other pozzolans were incorporated in the cement grout. The observations show that, although the mechanism of stress transfer is believed to be different from conventional concrete, the mortar strength is a controlling factor in the strength of TSC.

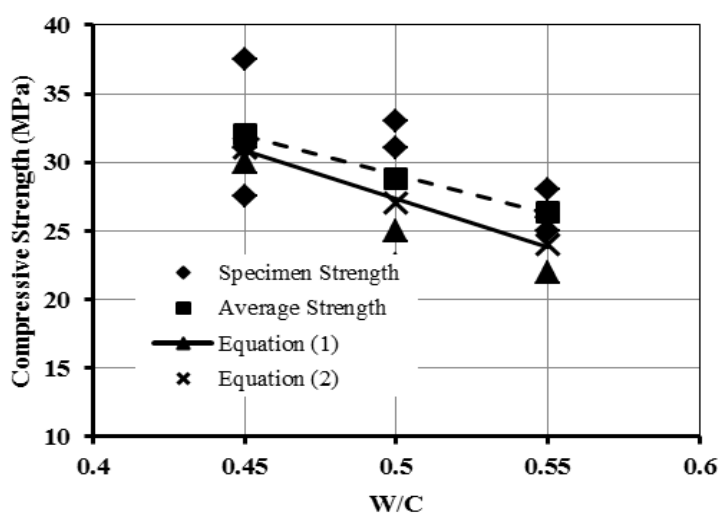

Fig. 3. Compressive strength versus w/c ratio

Table 2 summarizes the average compressive strength of mortar and concrete at 28 days. Firstly, it can be seen that the measured compressive strength at 28 days is sometimes high for both mortar and concrete. Secondly, the ratio of average concrete-to-mortar strengths is reasonably consistent and calculates from 0.50 to 0.51 for all mixtures at 28 days. This observation suggests that the compressive strength of two-stage concrete can be conservatively estimated as one-half of its mortar strength. If this ratio can be substantiated with more mixtures and other sources of coarse aggregate, this simple rule-of-thumb can be adopted in the design of two-stage concrete.

Table 2. Average compressive \& tensile strength

\begin{tabular}{|c|c|c|}
\hline W/C & $\begin{array}{c}\text { Compressive } \\
\text { Strength }\left(\mathrm{fc}^{\prime}\right) \\
(\mathrm{MPa})\end{array}$ & $\begin{array}{c}\text { Tensile Strength }\left(f_{t}\right) \\
(\mathrm{MPa})\end{array}$ \\
\hline 0.45 & 31.9 & 3.21 \\
\hline 0.45 & 30 & 3.11 \\
\hline 0.45 & 25.1 & 2.73 \\
\hline
\end{tabular}

Table 2 shows the average splitting tensile strengths of three specimens per w/c ratio at age of 28 days. The results indicate strength reduction as the w/c ratio increases. However, there appears to be little difference in strength between specimens produced with a w/c ratio of 0.45 and those produced with a w/c ratio of 0.50 . This was also observed with the compressive strengths measured for the same grout mixtures. The actual values of tensile strength at w/c ratios of 0.45 and 0.50 measured from 3.1 to $3.3 \mathrm{MPa}$, which indicate satisfactory results, especially when one considers the minimum cost of concreting and that no vibration tools are used. Furthermore, excellent results can be expected even when using a high w/c ratio of 0.55 , where the mean tensile strength is nearly $2.73 \mathrm{MPa}$. Test observations show that failure in splitting tension was restricted principally to the line of split and occurs through the mortar and coarse aggregate. Visual assessments of the failed specimens suggest that the percentage of failed aggregate increased in concrete with higher mortar strength. 


\subsection{Compressive-tensile strength relationships}

Knowing the compressive strength ( $\mathrm{fc}^{\prime}$ ) of concrete the tensile strength (ft) of conventional concrete can be predicted by using ACI code formula as shown in Equation (3). In this investigation Equation (4) was derived from TSC data to predict the splitting tensile strengths $\left(\mathrm{ft}^{\prime}\right)$.

$$
\begin{aligned}
& f_{t}^{\prime}=0.56 \sqrt{f_{c}^{\prime}} \\
& f_{t}^{\prime}=(0.55-0.56) \sqrt{f_{c}^{\prime}}
\end{aligned}
$$

Results from Equation (4) indicated that splitting tensile strength could be well estimated using the ACI equation presented in Equation (3). Comparison between results from this investigation and another investigation conducted by the authors [13] showed a clear similarity as presented in Figure 4. The data from both studies show that the tensile strength of TSC is at least as high as that of conventional concrete, and in fact it can be higher depending on the selection and properties of the coarse aggregate. No causes were apparent for the relatively higher tensile strength in two-stage concrete. However, the greater mechanical interlocking among particles in two-stage concrete could be responsible for the higher tensile strength since factors like aggregate gradation are different from conventional concrete. These observations warrant a much deeper investigation into the influence of coarse aggregate properties on two-stage concrete behaviour in tension. The results obtained in the study corroborate the research findings by Awal [14].

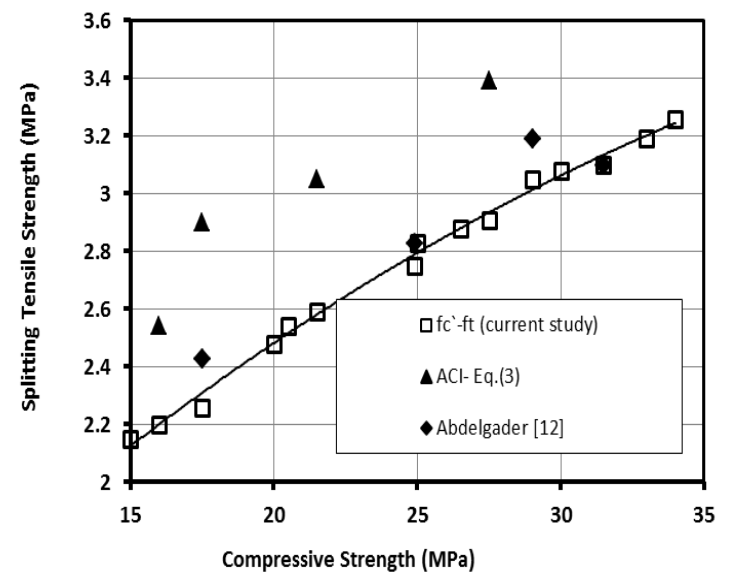

Fig. 4. Compressive strength versus tensile strength of TSC

\subsection{Stress-strain relationships}

The obtained results are statistically analyzed to estimate equations for the compressive strain-stress relations of various two-stage concrete types. The statistical analysis is performed by use of the MINITAB program [15]. The Minitab Regress Package fits an equation to the experimental data by the least square method. The calculation can be divided into the following steps: assumption of the mathematical relation, estimation of the equation coefficients, testing of the assumed equation and choice of the best model. The statistical analysis of the TSC test data is performed in two successive phases. First, equations for stress-strain relations for type of coarse aggregate and different grout proportions are estimated. In this step the data consist of 27 stress-strain sets of experimental results obtained from cylinder compressive tests [16, 17]. After various trials the following simple relation for all concrete types is:

$$
\hat{\sigma}=a \varepsilon_{1}^{3}+b \varepsilon_{1}^{2}+c \mathcal{E}
$$

In the above formulae $\sigma$ sands for the estimated concrete stresses and $\varepsilon$ denotes the concrete strain. The constants $\mathrm{a}, \mathrm{b}$, and $\mathrm{c}$ in Equation(5) for round aggregate and each concrete type are statistically obtained and presented in Table 3 for $\mathrm{c} / \mathrm{s}=1 / 1.5$ and various w/c ratios. Equation (5) gives reliable results in the strain range from 0 to 0.001 . Figure 5 presents typical results of stress and strain relation for round type of aggregate [16].

Table 3. Constants a, b, c of Equation (5)

\begin{tabular}{|c|c|c|c|c|c|}
\hline $\begin{array}{c}\text { Aggregate } \\
\text { Type }\end{array}$ & w/c & $\mathrm{a}$ & $\mathrm{b}$ & $\mathrm{c}$ & $\begin{array}{c}\text { Correlation } \\
\text { Coefficient }\end{array}$ \\
\hline & 0.45 & 18.2 & -32.5 & 34.0 & 0.9941 \\
\hline Round & 0.5 & 1.0 & -9.4 & 28.5 & 0.9978 \\
\hline & 0.55 & 5.81 & -22.0 & 32.1 & 0.9861 \\
\hline
\end{tabular}

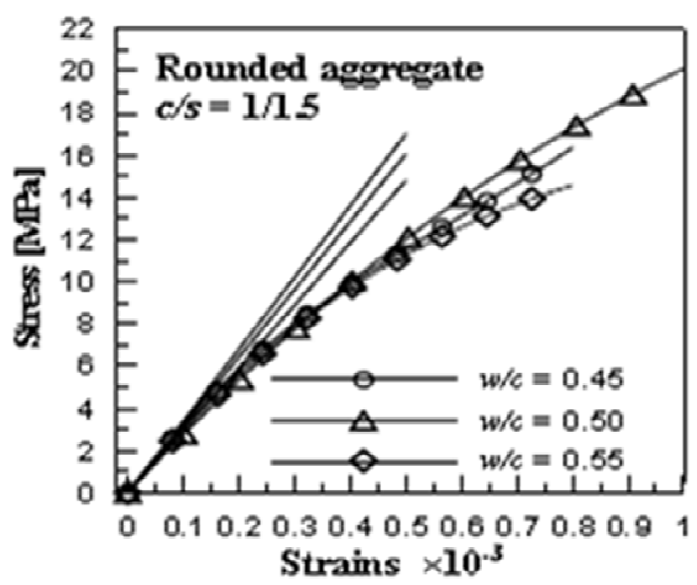

Fig. 5. Graphical presentation of stress-strain results of TSC

In the second step the statistical analysis is used to obtain the TSC stress-strain relations as function of watercement $(\omega=\mathrm{w} / \mathrm{c})$ and cement-sand $(\varsigma=\mathrm{c} / \mathrm{s})$ ratios. After a complex analysis the functions: $a=a(\omega, \varsigma), b=b(\omega, \varsigma)$ and $c=c(\omega, \varsigma)$ in Equation (5) are assumed for round aggregate as follows:

$$
\begin{aligned}
& a(\omega, \varsigma)=14.9-17.1 \omega+1.89 \varsigma \\
& b(\omega, \varsigma)=-40.8+30.1 \omega+5.80 \varsigma \\
& c(\omega, \varsigma)=40.7-11.1 \omega-4.46 \varsigma
\end{aligned}
$$


Some estimation results for concrete stresses according to Equation (5) by use of functions presented in equation (6) is shown in Table 4.

Table 4. Constants calculated for Equation (5)

\begin{tabular}{|c|c|c|c|c|c|}
\hline $\begin{array}{c}\text { Aggr. } \\
\text { Type }\end{array}$ & $\mathrm{w} / \mathrm{c}$ & $a(\omega, \varsigma)$ & $b(\omega, \varsigma)$ & $c(\omega, \varsigma)$ & $\begin{array}{c}\text { Correl. } \\
\text { Co-eff. }\end{array}$ \\
\hline \multirow{4}{*}{ Crushed } & 0.45 & 8.47 & -21.83 & 34.49 & \multirow{2}{*}{0.808} \\
\cline { 2 - 5 } & 0.5 & 7.61 & -21.78 & 34.69 & 0.814 \\
\cline { 2 - 5 } & 0.55 & 6.76 & -21.73 & 34.89 & 0.735 \\
\hline \multirow{3}{*}{ Round } & 0.45 & 10.8 & -23.39 & 32.73 & 0.827 \\
\cline { 2 - 5 } & 0.5 & 8.24 & -21.88 & 32.18 & 0.797 \\
\cline { 2 - 5 } & 0.55 & 5.68 & -20.38 & 32.62 & 0.652 \\
\hline
\end{tabular}

The test observations and the statistical analysis have proved that the linear part of the stress-strain curve in TSC may reach $85 \%$ of the ultimate cylinder strength (Figure 5). This may result from a very good contact between the aggregate particles. In consequence the applied load is distributed mainly by the stones. During the laboratory tests it was observed that the skeleton of the two-stage concrete carried the load until the whole specimen collapsed.

It was the reason why the failure of the two-stage concrete was not sudden and explosive but rather gradual. The failure specimen showed extensive lateral expansion in the form of bulging. Thus the specific stress-strain characteristics of the TSC can be explained by a dominant influence of the rigid stone skeleton.

It should be pointed out that the stress-strain relations of traditional concrete result from transfer of stress through the mortar-aggregate uniform matrix. In the TSC there are no such uniform relations because the mechanical properties of TSC are mainly determined by the characteristics of the stone aggregate. Therefore, the subsequent fracture of the two-stage concrete takes place through the stone aggregate particles [17-19]. In the TSC the compressive stresses in the aggregate and in the grout cannot be equal. The compressive stress is influenced by the shear stresses occurring not only in the vertical section but also in the horizontal contact surfaces. The produced shear stress caused the tearing off of the aggregate grains from the grout.

It was also observed that some micro cracking or interfacial cracks were randomly distributed even before the specimens were subjected to load testing. It seems that these cracks were caused by bleeding, settlements of grout, or by shrinkage stresses induced by the drying process [14[. The cracks formed within the grout may be considered to be isolated or discontinuous.

\subsection{Modulus of elasticity}

The experimental data analysis and the statistically obtained stress-strain relations allow for formulating the relationship between the modulus of elasticity and the compressive strength of the TSC grout. The compressive strength (Table 1) is calculated according to the algorithm for designing the two-stage concrete proposed by the author [16]:

$$
\overline{f_{c}}=\beta_{0}+\beta_{1} \cdot \bar{f}_{g}^{\beta_{2}}
$$

Where: stands for compressive strength of grout (MPa), $\beta_{0}, \beta_{1}$ and $\beta_{2}$ are constants obtained from regression analysis and are given in other research by the author [13].The modulus of elasticity of the TSC is mainly affected by the physical properties of the coarse aggregate. The influence of the content of grout in the concrete is rather meaningless. It has been observed that the same factors that affect the compressive strength also alter the elastic modulus of the TSC. The elastic modulus is obtained from the analysis of the stress-strain curves for each type of stone aggregate and the mix proportions. The initial tangent modulus of elasticity of the TSC is found with reference to the tangent line drawn to the stress-strain curve at the starting point as presented in Fig. 5.

The modulus of elasticity of TSC $E_{t s c}\left(\varepsilon_{1}\right)$, determined as a function of strains $\varepsilon\left(\varepsilon_{1}=\varepsilon \cdot 10^{3} \quad\right)$, can be calculated in GPa from Equation (8) as follows:

$E_{t s c}\left(\varepsilon_{1}\right)=\frac{d \hat{\sigma}}{d \varepsilon_{1}}=3 \cdot a(\omega, \varsigma) \cdot \varepsilon_{1}^{2}-2 \cdot b(\omega, \varsigma) \cdot \varepsilon_{1}+c(\omega, \varsigma)$

Assuming that the concrete modulus is estimated as:

$$
E_{t s c}=c(\omega, \varsigma)
$$

Equation (9) indicates that the function $c(\omega, \varsigma)$ calculated according to Equation 6, determines the elastic modulus of the TSC. It should be mentioned that the values of the elastic modulus obtained for $30 \%$ of the cylinder ultimate strength are almost the same. In this way the initial linear feature of the strain-stress relation of the TSC has been proved. It is possible to elaborate an alternative version of the elastic modulus formulae. Making use of the regression analysis of the experimental data expressions describing the relationship between the elastic modulus and the compressive strength of the TSC the following assumption for round aggregate type can be made:

$E_{T S C}=28.7+0.08 f_{c}^{\prime}$

Where: $\mathrm{fc}^{\prime}$ is the cube compressive strengths. The limit value of the cube compressive strengths in equation (10) is:

$23 \mathrm{MPa} \leq \bar{f}_{\mathrm{c}} \leq 32 \quad(\mathrm{MPa})$

Equation (10) is graphically presented in Figure 6. It should be noticed that the obtained values of the modulus 
of elasticity are rather scattered. This can be explained by the random allocation of coarse aggregate in the forms. Nevertheless, Equation (10) allows for the approximate determination of the modulus of elasticity for the examined aggregate. It should be pointed out that the obtained results deviate at most $\pm 10 \%$ from the calculated mean values. Similar observations have been made by Awal [20].

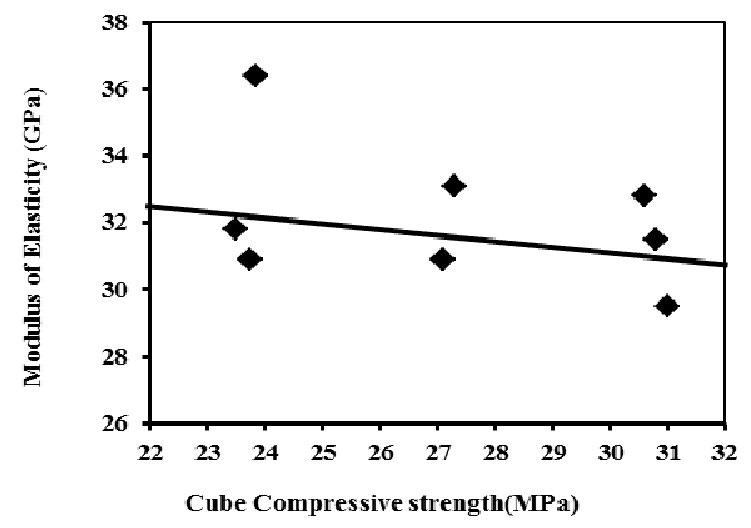

Fig. 6. Modulus of elasticity versus compressive strength

\section{CONCLUSIONS}

This paper presents sustainable production of two-stage concrete and highlights some physical and mechanical properties. Out of the results obtained and the observations made, the following are the conclusions drawn from the study:

$\square \quad$ A grout mixture with water-to-cement (w/c) ratios of 0.45 to 0.55 and a cement-to-sand $(\mathrm{c} / \mathrm{s})$ ratios of 1.0/1.5, 1.0/1.0 and 1.0/0.8 optimizes compressive and tensile strength of TSC. Mortar mixed with a w/c ratio below 0.42 is too viscous and does not fully penetrate the voids between coarse aggregate particles, thus creating a honeycombing effect in the hardened concrete. Even when partially bound, however, TSC provides strengths equivalent to that of fully bound concrete with mortar at w/c ratio of 0.45 .

$\square$ Compressive strength of TSC cylinders can be conservatively estimated as $50 \%$ of the mortar cube strength.

$\square \quad$ The splitting tensile strength of TSC was found to be similar to that predicted by the ACI equation for splitting tensile strength of conventional concrete. In some cases, the measured tensile strength of TSC is higher than that predicted by the ACI equation.

$\square$ The stress-strain relationships for different grout mixes (water/cement ratios and cement/sand ratios) do not show a big difference. The initial stress-strain curves can be estimated by linear relations. This may result from the stresses distributed mainly by the particles of stone aggregate (skeleton of stones). The specific way of stress transmission may also contribute to the initiation and propagation of cracks. $\square$ The modulus of elasticity as a function of compressive strength of the TSC is elaborated. The modulus values for specific type of aggregate are described by linear constant functions which allow engineers to design the TSC according to the algorithm.

\section{References}

1. Abdelgader, H., Khatib, J., El-baden, A., SelfCompacting Grout to Produce: Two-Stage Concrete, Proceeding of The 2nd International Sustainable Buildings Symposium, 367-372, Gazi University, Ankara, Turkey, (2015).

2. ACI Committee (304.1 R-92), Guide for the use of pre-placed aggregate concrete for structural and mass concrete applications: 21-24. Farmington Hills- Michigan: USA, (1997).

3. Abdelgader, H.S., Effect of quantity of sand on the compressive strength of two-stage concrete. Magazine of Concrete Research 48(3): 353-360, (1996).

4. Liu, C., Ahn, C.R., An, X. and Lee, S. Life-cycle assessment of concrete dam construction: comparison of environmental impact of rock-filled and conventional concrete, Journal of Construction Engineering Management, 139(12), (2013).

5. Samarin, A. Use of concrete as a biological shield from ionising radiation, Energy and Environmental Engineering, 1(2): 90-97 (2013).

6. ASTM. C33, Specification for concrete aggregates. American Society for Testing and Materials. Philadelphia: Pennsylvania, (1997).

7. ASTM-C150, Specification for Portland cement. American Society for Testing and Materials. Philadelphia: Pennsylvania, (1994).

8. Abdelgader, H.S., Elgalhud A. A., Effect of grout pro-portion on strength of two-stage concrete. Structural Concrete Journal 3(3): 163-170, (2008).

9. ASTM C942. Standard test method for compressive strength of grouts for preplaced-aggregate concrete in the laboratory. American Society for Testing and Materials. Philadelphia: Pennsylvania, (2010).

10. ASTM C873. Standard test method for compressive strength of concrete cylinders cast in place in cylinder molds. American Society for Testing and Materials. Philadelphia: Pennsylvania, (2010).

11. ASTM-C496/C496M. Standard test method for splitting tensile strength of cylindrical concrete specimen. American Society for Testing and Materials. Philadelphia: Pennsylvania, (2004).

12. Abdelgader, H.S., Górski, J. Influence of grout proportions on modulus of elasticity of two-stage concrete. Magazine of Concrete Research 4(5): 251255, (2002).

13. Abdelgader, H.S., Górski, J. Stress-strain relations and modulus of elasticity of two-stage concrete. ASCE Materials Journal 4(2): 251-255, (2003).

14. Awal, A.S.M.A. Manufacture and Properties of Prepacked Aggregate Concrete, M.Eng.Sc. Thesis, University of Melbourne, Australia (1985). 
15. Schaefer, R.L. \& Anderson, R.B. The student's edition of MINITAB statistical software adapted for education: 5-23. New York: Addison Wesley Company, (1989).

16. Abdelgader, H.S., How to design concrete produced by a two-stage concreting method. Cement and Concrete Re-search 3 (29): 331-337, (1999).

17. Iwasaki, N., Predictions of grouting process in prepacked concrete by green's function. Proceeding of Japanese Society of Civil Engineering: 45-50. Tokyo: Japan, (1985).

18. Awal, A.S.M.A. Failure mechanism of prepacked concrete. ASCE Structural Engineering Journal 3(5): 727-732, (1988).

19. Awal, A.S.M.A., Creep recovery of prepacked aggregate concrete, ASCE Journal of Materials in Civil Engineering, 4(3): 320-325, (1992).

20. Awal, A.S.M.A., Modulus of elasticity of prepacked aggregate concrete, Journal of Structural Engineering, Madras, India, 15(2) : 65-68, (1988). 